high mutation-rate in the first brood, followed by a steep drop from the first to the second brood $^{3}$; if third or fourth broods are sampled, they do not differ significantly from the spontaneous mutationrate.

While working at Pasadena, I carried out an experiment similar to the one described above as control to another experiment. Surprisingly, it was found that adenine had no effect on the mutagenic activity of formaldehyde, though the Drosophila stock was the same as that used in Edinburgh (Table 2). The only differing component in the two experiments was the strain of yeast used in the basic medium : in Edinburgh the yeast was Distillers' Co., Ltd. (D.C.L.), brewer's yeast, whereas in Pasadena it was the $K 2$ strain of Anheuser-Busch brewer's yeast, the yeasts in both cases being dry and heat-killed.

In an attempt to analyse this difference of effect, an experiment was carried out in which the adenine concentration in the basic medium containing the Anheuser-Busch strain of yeast was doubled, on the assumption that the adenine concentration previously used might be insufficient to produce its effect with this particular strain. No anti-mutagenic effect, however, resulted in this case.

The possibility remained that the Anheuser-Busch yeast might contain a chemical component in greater amounts than the D.C.L. strain, which might thus be masking the anti-mutagenic effect previously produced by adenine. To test this possibility, an experiment was carried out using the Anheuser-Busch strain, but halving its concentration. As seen from Table 3 , the antimutagenic effect of adenine towards formaldehyde returns, although the results are statistically significant only in the first brood.

This phenomenon, where the effectiveness of an anti-mutagen is conditional upon the strain (and concentration) of yeast employed, under what may otherwise be considered as standard cultural conditions, is clearly of importance in chemical mutation studies.

A detailed analysis of this and related phenomena is being published later. This work was carried out at the Institute of Animal Genetics, West Mains Road, Edinburgh 9, and while Gosney Research Fellow at the California Institute of Technology, Pasadena, California.

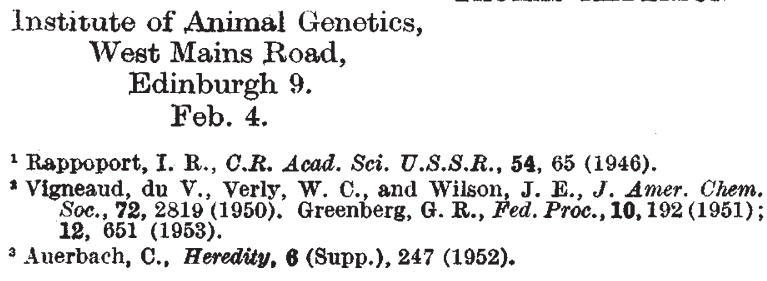

\section{Selection of a Strain of Plasmodium berghei highly resistant to Chloroquine ('Resochin')}

Is the past, numerous attempts to select strains of different plasmodia resistant to 4-aminoquinoline have been unsuccessful ${ }^{1}$. Recently, a successful attempt was recorded for Plasmodium gallinaceum, in which the resistance to chloroquine was found to be two-fold ${ }^{2}$. We have now succeeded in selecting a strain of mammalian plasmodium which is 200 times as tolerant to chloroquine as the parent strain.
The experimental selection of the strain was made in albino mice, the serial passages being exposed to progressively increasing doses of 'Resochin' solution administered intraperitoneally. The experiment involved 33 mouse passages during a period of about seven months. When the dose of drug administered reached $75 \mathrm{mgm}$. $/ \mathrm{kgm}$. body-weight of the mouse, it was found to be lethal to the mice, but the parasites in them were tolerant to it.

The degree of resistance was tested by standard methods and was found to be 200 -fold. 'The parent strain in infected mice, treated orally with $5 \mathrm{mgm} . /$ $\mathrm{kgm}$. body-weight twice daily for three consecutive days, disappeared from the peripheral blood for at least three consecutive days after the treatment. For a similar effect, mice infected with the resistant strain had to be treated orally with $1,000 \mathrm{mgm} . / \mathrm{kgm}$. twice daily for three days. The selection of the strain to higher doses of the drug could not be pursued as the dose proved to be lethal to the host.

Whether this successful selection of a strain of $P$. berghe $i$ in mice 200 times as tolerant to chloroquine as compared to the parent strain is attributable to the difference in physiology of the parasite from that of others, or to the difference in the pharmacology of the drug in mice from that in other animals, is not known.

The experimental details and discussion of the results are being published in the Indian Journal of Malariology.

\section{S. P. Ramakrishnan \\ Satya Prakash \\ D. S. Choudhury}

Malaria Institute of India, Delhi.

Jan. 27.

${ }^{1}$ Schmidt, L. H., Genther, C. S., Fradkin, R.: and Squires, Wanda, J. Pharm. Exp. Therap., 95, 382 (1949). Cooper, W. Co, Coatney. G. R., and Imboden, C. A., J. Nat. Mal. Soc., 9, 69 (1950). Bishop, A., and MeConnachie, E. W. Parasit., 42, 52 (1952).

${ }^{2}$ Ray, A. P., and Sharma, G. K., Nature, 178, 1291 (1956).

\section{Detection of Opaline Silica in Grass
Leaves}

ONE of us ${ }^{1}$ recently correlated the sizes and shapes of opaline silica particles in a pasture soil with those of silica bodies in the dominant grass. Finding that information in botanical literature is inadequate for making such correlations, we are investigating the opaline bodies of British grasses. In work on the leaf blades, we find that, unless appropriate techniques are employed, two main errors may arise : (1) the presence of opaline bodies are overlooked, or (2) if found, their shapes may be misinterpreted.

(1) For example, when using methods involving the separation of the upper and lower epidermis, we found ornamented rods in the leaf of Agrostis tenuis but could detect none in Cynosurus cristatus; yet, after treating with dilute chromic acid and mounting in canada balsam, the rods were equally conspicuous in both species. Once their presence in $C$. cristatus was known to us, we rendered the cellulose less prominent by immersing in a liquid of refractive index 1.50, after which some rods of opal could be seen on careful inspection.

(2) In Sieglingia decumbens, dumb-bell-shaped silica cells are visible at once in the separated epidermis (Fig. 1), but dilute chromic acid renders 